NBER WORKING PAPER SERIES

\title{
BUREAUCRACY AS A MECHANISM TO GENERATE INFORMATION
}

\author{
Walter Novaes \\ Luigi Zingales \\ Working Paper 9763 \\ http://www.nber.org/papers/w9763 \\ NATIONAL BUREAU OF ECONOMIC RESEARCH \\ 1050 Massachusetts Avenue \\ Cambridge, MA 02138 \\ June 2003
}

\begin{abstract}
We would like to thank Kathy Dewenter, Matthias Khal, Raghu Rajan, David Wessels, two anonymous referees, Raymond Deneckere (the editor) and participants at seminar at UCLA, PUC-Rio, and the 2001 LACEA meeting. Zingales gratefully acknowledges financial support from the Center for Research on Security Prices and the George Stigler Center at the University of Chicago for financial support. The views expressed herein are those of the authors and not necessarily those of the National Bureau of Economic Research.
\end{abstract}

(C2003 by Walter Novaes and Luigi Zingales. All rights reserved. Short sections of text not to exceed two paragraphs, may be quoted without explicit permission provided that full credit including $\bigcirc$ notice, is given to the source. 
Bureaucracy as a Mechanism to Generate Information

Walter Novaes and Luigi Zingales

NBER Working Paper No. 9763

June 2003

JEL No. D2, G3, L2

\section{$\underline{\text { ABSTRACT }}$}

Firms that maintain no formal record of actions and events would hardly be considered well managed. Yet, organizations that require the recording of actions and the filing of reports are often labeled "bureaucratic" and inefficient. This paper argues that the thin line between efficient management practices and inefficient bureaucracy is crossed to curb managerial agency costs in a multi-layer hierarchy. The model predicts that bureaucracy increases with the frequency of managerial turnover, and it establishes a link between bureaucracy, incentive schemes, and leverage in a cross-section of firms.

Walter Novaes

Department of Economics

Pontifical Catholic University of Rio de Janeiro (PUC-Rio)

Marques de Sãão Vicente 225

Rio de Janeiro

RJ, 22451-041, Brazil

novaes@econ.puc-rio.br

Luigi Zingales

University of Chicago, GSB

1101 E. 58th Street

Chicago, IL 60637

and NBER

luigi.Zingales@gsb.uchicago.edu 


\section{Introduction}

Weber (1968, p. 957) argues that "the management of the modern office is based upon written documents ('the files'), which are preserved in their original or draft form." In his view, a firm that maintains no formal record of actions and events would hardly be considered well managed. Yet, organizations that require the recording of actions and the filing of reports are often labelled "bureaucratic" and inefficient. This paper explores the balance between efficient management practices and inefficient bureaucracy. We show that this thin line is crossed to curb managerial agency problems in a multi-layer hierarchy.

In our model, a firm is run by a self-interested manager who, by organizing production, determines the extent to which employees' actions can be documented. Documenting actions is important because it allows for more effective incentive schemes. In organizing production, therefore, the manager must take into account that employees' effort should be used not only to increase production but also to maintain a system of incentives.

To better understand some of the trade-offs involved in improving a system of incentives, consider a commercial bank. The management of the bank can give loan officers complete discretion to approve loans, paying the officers solely on the basis of their portfolios' returns. Such organizational design probably maximizes the focus of the officers' effort on the bank's customers. Nonetheless, since the ex-post returns of a portfolio of loans is a noisy measure of performance, this compensation scheme imposes a great amount of risk on the loan officers. Alternatively, the bank could develop an information system that tracks employees' actions, generating information on the soundness of the loan officers' decision making process. In this alternative, loan officers may be rewarded not only for the returns of their portfolios but also on the basis of input-based performance measures that are more tightly linked to their actions: Did they try their best in evaluating the clients? Did they meet the bank's guidelines? This 
broader compensation scheme imposes a lower risk on the loan officers, making it easier to elicit effort.

Organizing an information system that documents corporate events also entails costs, however. For instance, although loan officers may find it useful to register conversations with their clients, avoiding ex post manipulations of these records is likely to require that loan officers write their reports not too long after a conversation takes place. Deadlines imply a loss of flexibility that affects the way that loan officers work. Hence, there exists a trade-off between effective incentive schemes and production efficiency.

Firms become overly bureaucratized when this trade-off is biased toward the benefits of improving incentives, implying the recording of corporate actions and events in too much detail. But why should this bias exist? We shall argue that the bias is an optimal response to managerial agency costs in a multi-layer organization.

Consider a three-layer hierarchy. The first layer (Board of Directors) chooses the incentive schemes for the second layer (manager) and the third layer (employee). The employee's contribution to the firm's production consists of an unobservable action, which we henceforth call effort. In turn, the manager organizes production, a task that determines the efficiency of the firm's information system. In making this organizational choice, the manager knows that a costly adjustment in the firm's production technology may increase the precision of an input-based signal of the employee's performance.

Besides the standard problem of providing incentives for the employee to exert effort, there is an agency problem at the manager's level. As Shleifer and Vishny (1989) point out, managers may choose projects that rely more heavily on their skills just to increase their bargaining power in a wage renegotiation. Likewise, managers may organize the firm in a way that their continuation at the company's helm is important to the employees' incentives. To understand what type of distortion this agency problem may imply, suppose that the firm is 
organized in a way that the employee's actions are recorded at a very high level of detail. The input-based measure of performance will then be very precise, making the employee confident that his effort will be rewarded despite events, like managerial turnover, that are outside his control. As a first approximation, the effectiveness of the system of incentives of a highly bureaucratized firm is independent of the manager's identity.

In contrast, a less bureaucratized firm has to rely more strongly on broader measures of performance (e.g., profits) to motivate the employee. This system of incentives is likely to be disrupted by managerial turnover. For instance, an employee under a profit-sharing compensation scheme may reduce effort if he realizes that profits will fall upon the hiring of a less efficient manager. The system of incentives of a less bureaucratized firm, therefore, is more severely disrupted by managerial turnover, making it more prone to be held up by the manager. To maximize her bargaining power vis-à-vis the Board of Directors, it is then in the manager's interest to bias the firm's organization toward very little record keeping, that is, an excessive degree of informality.

Whether this bias translates into an excessively informal organization depends upon the manager's own incentive schemes. Anticipating this bias, shareholders will want to link the manager's compensation to her choice of the firm's organization.

Yet, the optimal compensation contract will not implement an efficient organizational design. In an efficient organizational choice, the manager's quitting threat is not taken into account. In fact, efficiency ignores any transfer between the shareholders and the manager, focusing instead on the trade-off between production efficiency and incentives. From the view point of the shareholders, nonetheless, it pays to distort the organizational design to reduce transfers to the manager. As a result, shareholders distort the trade-off between production efficiency and generation of information toward the latter to improve the precision of the inputbased measure of performance. An excessively bureaucratic organization thus arises to reduce 
the manager's bargaining power. In other words, the best way to address a manager's bias toward very little record keeping implies the distortion of the organization in the direction of excessive record keeping.

Our paper builds upon a growing literature that views bureaucracy as a restriction on employees' behavior meant to reduce the cost of providing them with incentives. The papers in this literature share a common view on the final benefits of bureaucracy, but they differ on how these benefits are achieved. In Holmstrom and Milgrom (1991), bureaucratic rules reduce the cost of providing incentives because they restrict other activities that the employees would like to do, and in so doing they reduce their opportunity cost of effort. In Tirole $(1986,1992)$, rules reduce managers' discretion, decreasing the scope for collusion and, thus, reducing the cost of providing incentives. ${ }^{1}$ In Prendergast and Topel (1996), bureaucracy is a rule that distorts the weight attributed to a manager's report on her subordinate's performance. This distortion reduces the scope for favoritism in the organization. Finally, in Milgrom (1988) and Milgrom and Roberts (1990), bureaucracy precludes employees from influencing their supervisors' decisions, reducing wasteful rent-seeking.

In all these papers, the role of bureaucracy is either to destroy or to commit to ignore relevant information. By contrast, in our model, bureaucratic procedures - like the management by written documents that Weber describes - generate verifiable information, which can be used to improve the efficiency of incentive schemes. Thus, we focus on the role of bureaucracy as a mechanism to generate information. Perhaps more importantly, our model leads to new empirical implications. For example, while Tirole (1986) suggests that bureaucracy is negatively correlated with managerial turnover, our model predicts a positive correlation.

The remainder of the paper is organized as follows. Section 2 describes the model. Section 3

\footnotetext{
${ }^{1}$ The effect of rules on collusion is not unequivocal. If there is asymmetry of information between the manager and the employee, Felli (1996) shows that rules may actually increase collusion.
} 
characterizes efficient organizational choices and it obtains a one-to-one mapping between a firm's degree of bureaucratization and the extent to which employees' pay depends on measures of input rather than output. Section 4 explains why delegating the firm's organizational design to a self-interested manager generates an agency problem. Section 5 shows how overly bureaucratic firms arise in equilibrium. Section 6 discusses the empirical implications, and a conclusion follows in Section 7.

\section{Framework}

We consider a firm with a three-layer hierarchy: an employee whose contribution to production consists of his unobservable effort; a self-interested manager who, by organizing production, determines the extent to which the employee's contribution to the firm is verifiable; and a Board of Directors that acts in the interest of shareholders and makes sure that the firm is under optimal incentive schemes.

\section{Cash flow, preferences, and organizational design}

Our main interest in this paper is to investigate a trade-off between efficiency in production and generation of information. To characterize this trade-off, we relate the firm's cash-flow to the employee's incentive to exert effort, which is the ultimate reason for producing information in our model.

At one extreme, the manager can organize production to maximize the impact of the employee's effort on production. In this case, the firm's output is described by a stochastic production function, $x(a)$, that depends on the employee's effort, $a$. We assume that $x(a)$ is 
normally distributed with mean $a$ and standard deviation $\sigma<\infty$ :

$$
x(a) \sim N(a, \sigma) .
$$

By organizing the firm in this way, the manager generates only one signal of the employee's effort: the output itself. This represents a problem to the Board because, as in the standard Principal-Agent models, effort is unobservable for outsiders and costly for the employee. More precisely, the employee's preferences over effort, $a$, and income, $w$, are represented by

$$
U(w, a)=-e^{-r(w-c(a))}
$$

where $r$ is the coefficient of absolute risk aversion, and $c: \Re_{+} \rightarrow \Re_{+}$is a convex and twice continuously differentiable cost function with $c(0)=0, c^{\prime}(a)>0$ for $a>0$, and $c^{\prime}(0)=0$.

For the employee to exert effort, his compensation would have to be linked to the sole signal of effort, that is, the noisy output $x$. Since the employee is risk averse, shareholders must compensate him not only for the disutility of effort but also for the riskiness of the contract.

As Holmstrom (1979) demonstrates, the Board can enhance the efficiency of the employee's contract by including other measures of effort that are not perfectly correlated with output. Let us then call $y$ an input-based measure of the employee's performance, with

$$
y \sim N(a, \lambda)
$$

We assume that, conditioned on the employee's effort, $y$ and $x$ are independent. As a result, the value of the input-based measure of performance, $y$, is high if its standard deviation $\lambda$ is low.

In our model, the standard deviation of the input-based measure of performance, $\lambda$, summarizes the firm's organizational design. The input-based measure of performance has a low 
standard deviation in firms that organize production so that employees' actions are documented in detail. In contrast, an organizational design that maximizes production efficiency implies such a large standard deviation, call it $\lambda^{\max }$, that, for all practical purposes, makes $y$ a useless signal of the employee's effort. Increasing the precision of input-based performance measures thus implies sacrificing production efficiency.

To illustrate the interaction between production efficiency and input-based measures of performance, let us revisit the loan officer example. The soundness of a loan officer's decisionmaking process amounts to an input-based measure of performance. Of course, this performance measure will be meaningless unless the bank tracks the officer's lending practices. Doing so requires, among other things, that the loan officer document conversations with clients and provide reasons for credit approvals. Moreover, avoiding ex post manipulation of these reports requires inspections that change not only the loan officers' routine but also the job assignments of other employees in the bank. Clearly, such organizational design does not maximize the focus of the employees' efforts on the bank's customers.

We model the production costs associated with input-based performance measures by a twice continuously differentiable function $\Gamma:\left(\lambda^{\min }, \lambda^{\max }\right] \rightarrow \Re_{+}$. If the Board organizes the firm to maximize production efficiency, then $\lambda=\lambda^{\max }$ with $\Gamma\left(\lambda^{\max }\right)=0$. If, instead, the Board sacrifices production to increase the precision of the input-based measure of performance, then $\lambda<\lambda^{\max }$ and $\Gamma(\lambda)>0$. In other words, $\Gamma(\lambda)$ is a decreasing function of $\lambda$.

To assure interior solutions, we also assume that $\Gamma(\lambda)$ is a convex function with $\Gamma^{\prime}\left(\lambda^{\max }\right)=$ 0 , and $\lim _{\lambda \rightarrow \lambda^{\min }} \Gamma(\lambda)=\infty$. The firm's output is then characterized by a function, $x^{\prime}(a, \lambda)$, that depends on the employee's effort, $a$, and the organizational choice, $\lambda$, as follows:

$$
x^{\prime}(a, \lambda)=x(a)-\Gamma(\lambda) .
$$

For simplicity, shareholders and the manager are risk neutral. Hence, from the perspective 
of the shareholders, the optimal organizational choice maximizes expected profits. More interestingly, we shall show in Section 4 that the manager has incentive to distort the organizational design, despite assuming that the act of organizing the firm does not directly affect her utility function. Of course, selling the firm to the manager would eliminate her incentive to deviate from value-maximizing actions. To rule out this uninteresting solution to the agency problem, we assume that the manager is credit constrained. The manager has to remain as an employee of the shareholders, who must impose an incentive scheme on the manager to prevent her from distorting the firm's organizational design.

\section{Timing}

Figure 1 outlines the timing of the model and its main events. At date $t=0$, the Board chooses the manager's and the employee's compensation schemes to maximize expected profits. Contracts can be written on three variables: the output, $x^{\prime}$, the input-based signal of the employee's effort, $y$, and the organizational choice, $\lambda$.

Figure 1: Timing of events

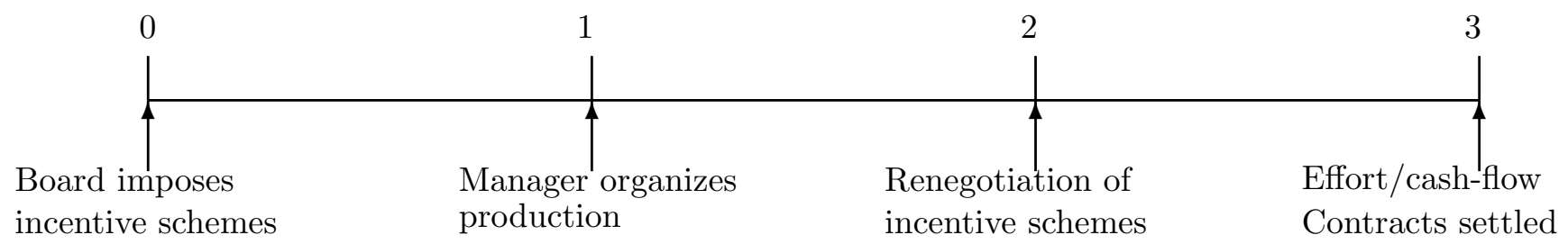

Changing a firm's organizational structure is likely to require time. Accordingly, one would expect that, once the manager implements the organizational design, there is a time lag to change it. In our single-production-period model, this time lag implies that the manager 
irreversibly chooses the organizational design at date $t=1$, when the precision of the inputbased measure of performance is also sunk. ${ }^{2}$

In contrast, we assume that the incentive contracts can be renegotiated at date $t=2$ after the manager implements the organizational design. This asymmetry lets us focus on the agency costs associated with the organizational design, as opposed to the literature on bureaucracy that focuses on the impact of collusive agreements on the optimal incentive schemes. (See, for instance, Tirole (1986) and Prendergast and Topel (1996).) Finally, output, $x^{\prime}$, and the input-based measure of performance, $y$, realize at date $t=3$ after the employee exerts effort.

\section{Organizational Design}

This section characterizes an efficient organizational design as a solution to a trade-off between the costs and benefits of increasing the precision of the input-based measure of performance. We solve this trade-off backwards. For any given organizational choice, we find the employee's optimal incentive scheme. This contract determines the firm's value as a function of the organizational design. An efficient organizational choice maximizes this value function.

\section{The employee's contract}

Given a firm's organizational choice, $\lambda$, the employee's optimal contract solves

$$
\max _{\{w(., .), a\}} E[x-\Gamma(\lambda)-w(x-\Gamma(\lambda), y) ; a, \lambda, \sigma]
$$

\footnotetext{
${ }^{2}$ While we agree that managerial turnover is likely to precipitate organizational changes, managers who want to use a quitting threat to obtain salary raises will do so when the threat is strong. Since the quitting threat is likely to be strong when the firms' reorganization costs are high, assuming that the organizational design is sunk may be interpreted as the incumbent optimally choosing the time to renegotiate the salary.
} 


$$
\begin{aligned}
& \text { subject to }(I R) E\left[-e^{-r(w(. . .)-c(a))} ; a, \lambda, \sigma\right] \geq-1, \\
& (I C) a \in \operatorname{argmax}_{a \in \Re_{+}} E\left[-e^{-r(w(. . .)-c(a))} ; a, \lambda, \sigma\right] .
\end{aligned}
$$

The objective function is the firm's expected profit gross of the manager's wage. When solving for the employee's optimal contract, we can ignore the manager's salary because all of her actions are sunk at the time that effort has to be elicited. Thus, any distortion that the manager's salary may impose on the employee's effort would be renegotiated away at the proper time. The participation constraint (IR) assures that the contract satisfies the employee's reservation value, which we assume to be -1 , while the incentive compatibility constraint (IC) provides the correct incentives for the employee to exert effort.

For simplicity, we restrict attention to linear compensation contracts:

$$
w\left(x^{\prime}, y\right)=\alpha+\beta_{1} x^{\prime}+\beta_{2} y .
$$

Thanks to the linearity of the contract, we can replace the incentive compatibility constraint (IC) by the first order condition of the employee's effort decision. Furthermore, the participation constraint (IR) will be binding (because the objective function decreases with the manager's wage), allowing us to substitute it into the objective function. As a result, we can rewrite the program as

$$
\begin{gathered}
\max _{\left\{\beta_{1}, \beta_{2}, a\right\}} a-c(a)-\frac{r}{2}\left[\beta_{1}^{2} \sigma^{2}+\beta_{2}^{2} \lambda^{2}\right]-\Gamma(\lambda) \\
\text { subject to } \quad c^{\prime}(a)=\beta_{1}+\beta_{2} .
\end{gathered}
$$

The first order conditions (which are also sufficient) of program (1) are

$$
\begin{gathered}
1-c^{\prime}(a)\left[1+r \frac{(\sigma \lambda)^{2}}{\sigma^{2}+\lambda^{2}} c^{\prime \prime}(a)\right]=0, \\
\beta_{1}=\frac{c^{\prime}(a)}{1+\left(\frac{\sigma}{\lambda}\right)^{2}}, \text { and }
\end{gathered}
$$




$$
\beta_{2}=\frac{c^{\prime}(a)}{1+\left(\frac{\lambda}{\sigma}\right)^{2}}
$$

The first order conditions imply the standard under-provision of effort; the optimal contract sacrifices some effort to reduce the dollar amount that should be paid to the employee as a compensation for the risk imposed by the incentive contract. Moreover, since an increase in the volatility of output, $\sigma$, makes the output-based measure of performance noisier, the optimal response is to decrease the weight of output, $\beta_{1}$, in the employee's compensation.

The impact of an increase in the volatility of the output on the weight of the inputbased measure, $\beta_{2}$, is ambiguous. Increasing the volatility of output imposes more risk on the employee. To facilitate risk sharing, the optimal contract induces a lower level of effort which, in turn, reduces the urge for a high power incentive scheme. Thus, an increase in the volatility of output may result in a lower weight on the input-based performance measure $y$. Still, dividing equations (3) and (4) yields equation (5), below, which shows that, upon an increase in the volatility of the output, the weight of the input-based performance measure increases relative to the weight of the output-based measure of performance.

$$
\frac{\beta_{2}^{\star}(\lambda, \sigma)}{\beta_{1}^{\star}(\lambda, \sigma)}=\left(\frac{\sigma}{\lambda}\right)^{2} .
$$

Analogous results follow for an increase in the volatility $\lambda$ of the input-based measure of performance: The optimal effort and the weight on the input-based performance measure $\left(\beta_{2}^{\star}\right)$ fall, $\frac{\beta_{2}^{\star}(\lambda, \sigma)}{\beta_{1}^{\star}(\lambda, \sigma)}$ decreases, while the effect on $\beta_{1}^{\star}$ is ambiguous.

\section{Organizational design and bureaucracy}

Given an organizational choice $\lambda$ and the volatility $\sigma$ of the firm's output, let the expected profit (gross of the manager's salary) be $V(\lambda, \sigma)-\Gamma(\lambda)$, where

$$
V(\lambda, \sigma) \equiv \max _{\left\{a, \beta_{1}, \beta_{2}\right\}} a-\left[c(a)+\frac{r}{2}\left(\beta_{1}^{2} \sigma^{2}+\beta_{2}^{2} \lambda^{2}\right)\right] \quad \text { subject to } \quad c^{\prime}(a)=\beta_{1}+\beta_{2}
$$


An efficient organizational design solves

$$
\max _{\lambda \in\left(\lambda^{\min }, \lambda^{\max }\right]} V(\lambda, \sigma)-\Gamma(\lambda)
$$

As it turns out, it pays to distort production efficiency to improve the firm's system of incentives. To see this, just note that a trivial application of the envelope theorem implies that $\frac{\partial V(\lambda, \sigma)}{\partial \lambda}=-r \beta_{2}^{2} \lambda$, which is negative for any $\lambda \in\left(\lambda^{\min }, \lambda^{\max }\right]$. Since, by assumption, $\frac{\partial \Gamma\left(\lambda^{\max }\right)}{\partial \lambda}=0$, expected profits increase if production is marginally distorted $\left(\lambda<\lambda^{\max }\right)$ to increase the precision of the input-based measure of performance.

It then follows that any solution to Program (7) must lie in the open interval $\left(\lambda^{\min }, \lambda^{\max }\right)$, implying the first order condition ${ }^{3}$

$$
\frac{\partial V\left(\lambda^{e f f}, \sigma\right)}{\partial \lambda}=\frac{\partial \Gamma\left(\lambda^{e f f}\right)}{\partial \lambda}
$$

Because $V(\lambda, \sigma)-\Gamma(\lambda)$ is not necessarily quasi-concave, there may be multiple equilibria in the organizational design problem. Two efficiently organized firms, therefore, may present different degrees of bureaucracy. As such, we will say that firm $A$ is more bureaucratized than firm $B$ if the organizational design of firm $A$ ends up documenting the employee's actions at a greater level of detail, leading to a lower volatility of the input-based measure of performance, that is, $\lambda^{A}<\lambda^{B}$.

From equation (5), if firms $A$ and $B$ have the same volatility of output but firm $A$ is more bureaucratized $\left(\lambda^{A}<\lambda^{B}\right)$, the weights of the firms' output- and input-based measures of performance must satisfy

$$
\frac{\beta_{2}^{\star}\left(\lambda^{A}\right)}{\beta_{1}^{\star}\left(\lambda^{A}\right)}=\left(\frac{\sigma}{\lambda^{A}}\right)^{2}>\left(\frac{\sigma}{\lambda^{B}}\right)^{2}=\frac{\beta_{2}^{\star}\left(\lambda^{B}\right)}{\beta_{1}^{\star}\left(\lambda^{B}\right)} .
$$

\footnotetext{
${ }^{3}$ To solve Program (7), we can restrict attention to values of $\lambda$ in the interval $\left[\lambda^{\min }+\epsilon, \lambda^{\max }\right]$, where $\epsilon$ is as close to zero as needed. This restriction on the opportunity set is without loss of generality because $V(\lambda, \sigma) \leq \max _{a}\{a-c(a)\}<\infty, \Gamma^{\prime}(\lambda)<0$, and $\lim _{\lambda \rightarrow \lambda^{\min }} \Gamma(\lambda)=\infty$. Existence of a solution to Program (7) then follows from continuity of the expected profit and compactness of $\left[\lambda^{\text {min }}+\epsilon, \lambda^{\text {max }}\right]$.
} 
Conditioned on the volatility of output, $\sigma$, there is then a one-to-one correspondence between a firm's degree of bureaucratization and the relative slopes of the employee's incentive scheme: The more bureaucratized a firm is, the larger the importance of input-based measures of performance in the employee's compensation.

While it is hard to differentiate between types of organizational design, it should be less difficult to measure the outcome of a bureaucratic system, that is, the extent to which employees' pay depends on measures of input rather than output. Our framework thus yields an empirical proxy for a company's degree of bureaucratization: the relative weights of the input and output measures of performance. According to this measure of bureaucracy, a more bureaucratic bank will make a loan officer's compensation scheme more sensitive to how well he follows the bank's credit procedures, while the compensation of a less bureaucratic bank will be more sensitive to the profits of the officer's portfolio.

\section{Conflicts of Interest in the Level of Bureaucracy}

\section{The manager's quitting threat}

Even if the managerial labor market is competitive, once in control, a manager has many ways to acquire some power vis-à-vis the Board and use it to extract rents in a wage renegotiation. ${ }^{4}$ To focus our attention on the costs and benefits of producing information, we model the source of the manager's power by assuming that the volatility of output increases with the manager's departure. With a noisier measure of performance, the employee's incentive scheme becomes less effective, leading to a drop in profitability. By threatening to impose this loss on the firm, a manager can negotiate a higher wage.

\footnotetext{
${ }^{4}$ Shleifer and Vishny (1989), for instance, suggest that an appropriate selection of which projects to undertake would make the manager more indispensable to the firm's operations.
} 
Our loan officer example may help illustrate the interaction between managerial turnover and volatility of output. One of the roles of a loan officer is to detect early credit problems and take appropriate remedial actions (e.g., making sure that, in case of default, the bank will be able to seize any collateral). Deciding whether to act on a signal of credit problems is often a subjective call, though. On the one hand, early actions may reduce the bank's loss in case the firm becomes financially distressed. On the other hand, they may jeopardize a profitable business relationship. Accordingly, one would expect that loan officers share remedial management decisions with their supervisors, who, in turn, have to rely on the loan officers' beliefs to make the decisions.

Conceivably, a conservative loan officer is likely to draw a less rosy picture of the client's financial situation than a more marketing oriented officer would. Hence, supervisors should take into account their subordinates' characteristics when deciding whether to take early remedial actions. Clearly, a new supervisor who has not had enough time to know the loan officer will be at disadvantage on this regard. Managerial turnover should thus imply a reduction in the expected return of the officer's portfolio and an increase in the volatility of returns. For simplicity, we ignore the mean effect and concentrate on the increased variance. ${ }^{5}$ Output under a replacement manager is then equal to

$$
x_{R}(a)-\Gamma(\lambda) \sim N(a-\Gamma(\lambda), \bar{\sigma}),
$$

with $\bar{\sigma}>\sigma$.

To facilitate risk sharing, the optimal employee's contract responds to a higher volatility of output by eliciting a lower level of effort. This reduction of effort moves the firm away from

\footnotetext{
${ }^{5}$ This assumption is consistent with Warner, Watts, and Wruck (1988), who find an increase in the volatility of stock returns around a managerial turnover event but no abnormal stock returns. Matthew, Hartzell, and Rosenberg (2000) also find that CEO turnover significantly increases the volatility of stock returns.
} 
the first best, reducing its value by: ${ }^{6}$

$$
[V(\lambda, \sigma)-\Gamma(\lambda)]-[V(\lambda, \bar{\sigma})-\Gamma(\lambda)]=V(\lambda, \sigma)-V(\lambda, \bar{\sigma})>0
$$

Note that the reduction in firm value will be higher if the Board does not renegotiate the employee's contract. After all, $V(\lambda, \bar{\sigma})$ - the firm's value after optimally resetting the employee's contract — is an upper bound under the higher volatility $\bar{\sigma}$. Whether the employee's contract is reset or not, the loss in value associated with managerial turnover gives some bargaining power to the incumbent manager, who can threaten to quit if she does not obtain a salary raise.

As in Shleifer and Vishny (1989), we assume that any salary negotiation between the Board and the manager will be efficiently resolved, with the manager staying in the firm and capturing a fraction $\phi \in(0,1]$ of the loss that her departure would have imposed on the firm's value. One interpretation for the manager's ability to extract a pay raise is that outsiders may think that the drop in firm value after managerial turnover is the result of the loss of a skillful manager. Accordingly, the manager's payoff from the renegotiation game may be viewed as the present value of the increase in the incumbent manager's outside option upon managerial turnover.

For any given organizational choice $\lambda$, the manager will try to renegotiate whenever her expected salary is below $\phi\{V(\lambda, \sigma)-V(\lambda, \bar{\sigma})\}$; a threshold that takes into account that the Board will optimally reset the employee's compensation contract in case of managerial turnover.

\section{Organizational design and managerial rent}

So far,we have just pointed out that, left unchecked, the manager's quitting threat assures her

\footnotetext{
${ }^{6}$ To show that an increase in the volatility of output reduces value after optimally resetting the employee's contract, use the envelope theorem to differentiate $V(\lambda, \sigma)$, equation (6), with respect to $\sigma$ and obtain $\frac{\partial V(\lambda, \sigma)}{\partial \sigma}=$ $-r\left(\beta_{1}^{\star}\right)^{2} \sigma<0$.
} 
some rents. Do the rents affect the manager's choice of the organizational design? We now show that, under a mild assumption, the manager can enhance the quitting threat by running an excessively informal firm.

Let $\bar{\lambda}^{e f f}$ be the most informal organizational design that maximizes firm value (i.e., $\bar{\lambda}^{e f f}$ is the largest solution to Program (7)). For any bargaining power $\phi>0$, the manager's gain in a salary renegotiation increases with the loss that managerial turnover causes to the firm's value. Hence, the manager has incentives to run an excessively informal firm $\left(\lambda>\bar{\lambda}^{\text {eff }}\right)$ if bureaucracy reduces the efficiency loss associated with her departure. Using the envelope theorem to differentiate the firm's value (see equation (6)), one can check that this condition is satisfied if

$$
\frac{\partial^{2} V(\lambda, \sigma)}{\partial \lambda \partial \sigma}=-2 r \sigma \beta_{1}(\lambda, \sigma) \frac{\partial \beta_{1}(\lambda, \sigma)}{\partial \lambda}<0
$$

The above inequality holds if and only if $\frac{\partial \beta_{1}(\lambda, \sigma)}{\partial \lambda}>0$. Intuitively, a more informal organizational choice (higher $\lambda$ ) increases the loss that the manager's departure imposes on shareholders if it makes the employee's contract rely more heavily on the output-based measure of performance, which will capture the increase in the volatility associated with managerial turnover. Since $\frac{\partial^{2} V(\lambda, \sigma)}{\partial \lambda \partial \sigma}=\frac{\partial^{2} V(\lambda, \sigma)}{\partial \sigma \partial \lambda}$, it follows that

$$
-2 r \sigma \beta_{1}(\lambda, \sigma) \frac{\partial \beta_{1}(\lambda, \sigma)}{\partial \lambda}=-2 r \lambda \beta_{2}(\lambda, \sigma) \frac{\partial \beta_{2}(\lambda, \sigma)}{\partial \sigma}
$$

and so $\frac{\partial \beta_{1}(\lambda, \sigma)}{\partial \lambda}>0$ if and only if $\frac{\partial \beta_{2}(\lambda, \sigma)}{\partial \sigma}>0$.

We have argued in Section 2 that the signs of $\frac{\partial \beta_{1}(\lambda, \sigma)}{\partial \lambda}$ and $\frac{\partial \beta_{2}(\lambda, \sigma)}{\partial \sigma}$ are ambiguous. These signs are ambiguous because an increase in volatility enhances the risk borne by the employee, making the optimal incentive scheme elicit a lower amount of effort. Less powerful incentive schemes result, implying that, for example, $\beta_{2}(\lambda, \sigma)$ may decrease with the volatility of output, despite a higher relative precision of the input-based measure of performance.

Assumption 1, below, imposes a lower bound on the sensitivity of the employee's effort with 
respect to the volatility of output. This lower bound, which depends on the curvature of the employee's cost function, assures that the weight of the input-based measure of performance, $\beta_{2}^{\star}$, increases with the volatility of output.

Assumption 1. For any effort $a$, the employee's cost of exerting effort satisfies $\frac{a c^{\prime \prime}(a)}{c^{\prime}(a)} \leq k \in \Re_{+}$.

Moreover, for any $(\lambda, \sigma)$, the elasticity of $a^{\star}$ with respect to $\sigma$ satisfies $-\frac{\partial a^{\star}}{\partial \sigma} \frac{\sigma}{a^{\star}}<\frac{2}{k} \frac{\left(\lambda^{m i n}\right)^{2}}{\left(\lambda^{m i n}\right)^{2}+(\sigma)^{2}}$.

Given Assumption 1, which is satisfied by the quadratic cost function when $\lambda^{\min } \geq \sigma$, we have: ${ }^{7}$

Proposition 1. Under Assumption 1, the manager has incentive to run an excessively informal organization. If $\tilde{\lambda}$ is the manager's unconstrained organizational choice and $\bar{\lambda}^{e f f}$ is the most informal efficient organizational design then,

$$
\bar{\lambda}^{e f f}<\tilde{\lambda} \in \operatorname{argmax}_{\lambda \in\left(\lambda^{\min }, \lambda^{\max }\right]} \phi\{V(\lambda, \sigma)-V(\lambda, \bar{\sigma})\}
$$

Proof. See the Appendix.

From Proposition 1, the manager has incentive to run an excessively informal firm. (See Edlin and Stiglitz (1995) and Prendergast (1995) for two other examples of how managers may reduce firm value to extract salary concessions.) To prevent the manager from distorting the organizational design, the Board must give her an incentive contract. A salary $s(\lambda)$ that is contingent on the organizational choice appears as a natural candidate for an optimal incentive scheme. In particular, one might think that, under a competitive managerial labor market,

\footnotetext{
${ }^{7}$ The exponential cost function does not satisfy $\frac{a c^{\prime \prime}(a)}{c^{\prime}(a)} \leq k \in \Re_{+}$if the set of employee's effort is unbounded. Yet, the weight of the input-based measure of performance, $\beta_{2}(\lambda, \sigma)$, increases with $\sigma$ if $c(a)=e^{a}-1$. In other words, Assumption 1 is sufficient but not necessary.
} 
the first best obtains under a forced contract that pays the manager her reservation value if and only if she chooses an efficient organizational structure.

Note, however, that if we realistically assume that a contract that penalizes an employee for quitting is not enforceable, then the manager can choose an efficient organizational structure and still threaten to quit. Therefore, a contract that elicits an efficient choice $\lambda^{\text {eff }}$ must give the manager a rent that is at least equal to

$$
\phi\left\{V\left(\lambda^{e f f}, \sigma\right)-V\left(\lambda^{e f f}, \bar{\sigma}\right)\right\}
$$

If the manager is unable to pay up front the value of her future rents, shareholders may find it too costly (in terms of managerial rents) to elicit an efficient organization design. In fact, as the next section shows, shareholders are better off with an organizational design that is overly bureaucratized.

\section{Bureaucracy as a Mechanism to Reduce Managerial Rents}

The Board's problem at date 0 is to maximize the firm's expected profits by choosing an organizational design, $\lambda^{s b}$, and a compensation scheme that pays the manager $s\left(\lambda^{s b}\right)$ if $\lambda^{s b}$ is implemented and a harsh penalty otherwise. The compensation scheme, therefore, is not a smooth function of the manager's organizational choice. In this setting, the Board will solve

$$
\begin{gathered}
\max _{\{s(\lambda), \lambda\}} V(\lambda, \sigma)-\Gamma(\lambda)-s(\lambda) \\
\text { subject to } s(\lambda) \geq \phi\{V(\lambda, \sigma)-V(\lambda, \bar{\sigma})\} .
\end{gathered}
$$

The objective function is the firm's expected profit at date $t=0$ given the Board's choice of the manager's incentive compensation, $s(\lambda)$, and the organizational design $\lambda$. The board chooses the compensation scheme and the organizational design to maximize expected profits 
while satisfying the manager's participation constraint. In other words, given the pair $(s(),. \lambda)$, the manager should not have incentive to breach the contract, asking for a pay raise under a quitting threat.

Since the manager's compensation decreases the expected profits, the participation constraint will be binding at the optimum. After replacing the constraint in the objective function, the Board's problem becomes

$$
\max _{\left\{\lambda \in\left(\lambda^{\min }, \lambda^{\max }\right]\right\}} V(\lambda, \sigma)-\Gamma(\lambda)-\phi[V(\lambda, \sigma)-V(\lambda, \bar{\sigma})] .
$$

From equation (9), one can easily see that the manager's compensation schedule is irrelevant to the Board's decision. All that matters is the manager's reservation value, which is a function of the firm's organizational design. As such, the compensation scheme $s(\lambda)$ may be interpreted as the manager's expected payoff from any contract that elicits the desired organizational choice $\lambda$. For instance, $s(\lambda)$ may be the manager's expected payoff from some sharing rule that splits the firm's profits between the manager and shareholders. The only requirement is that the sharing rule alone cannot eliminate all agency problems, as it would be the case if shareholders could sell the firm to the manager.

A necessary condition for an interior solution to Program (9) is

$$
\frac{\partial V}{\partial \lambda}\left(\lambda^{s b}, \sigma\right)=\frac{\partial \Gamma\left(\lambda^{s b}\right)}{\partial \lambda}+\phi\left[\frac{\partial V}{\partial \lambda}\left(\lambda^{s b}, \sigma\right)-\frac{\partial V}{\partial \lambda}\left(\lambda^{s b}, \bar{\sigma}\right)\right]
$$

As Proposition 2 shows, any solution to Program (9) implies that the firm will be overly bureaucratized.

Proposition 2. Under Assumption 1, the shareholders' choice of the organizational design implies that the firm will be overly bureaucratized, that is, if $\lambda^{s b}$ solves Program 9 and $\underline{\lambda}^{e f f}$ is the most bureaucratized organizational design that maximizes firm value, then $\lambda^{s b}<\underline{\lambda}^{e f f}$. 
Proof. See the Appendix.

The intuition for Proposition 2 is simple. Since the disruption of incentive schemes upon managerial turnover is the source of the manager's bargaining power, minimizing this disruption reduces managerial rents. Bureaucracy provides one way to reduce the disruption of managerial turnover on the firm's system of incentives. Thus, reducing managerial rents induces the Board to choose an organizational design that is overly bureaucratized.

\section{Extensions and Discussion}

\section{Bureaucracy and managerial turnover}

In our basic model, the incumbent manager is not replaced in equilibrium. Yet, managerial turnover is a relatively common corporate event. Denis and Denis (1995), for instance, report a $17 \%$ managerial turnover rate for a sample of 1,689 firms in the Value Line Sample. There are several reasons for managerial turnover to occur. For one, managers do not live for ever; with age comes retirement and death. Moreover, changes in the business environment may require new managerial skills, leading shareholders to replace the incumbent management despite the weakening of the system of incentives.

To investigate the interaction between managerial turnover and the organizational-design problem, let $\Pi$ be an exogenous probability of managerial turnover. For instance, $\Pi$ may reflect the probability that some change in the business environment requires managerial skills that the current manager does not have. Given $\Pi$, the Board should choose the manager's compensation scheme and the organizational design to solve

$$
\max _{\{s(\lambda), \lambda\}}(1-\Pi)\{V(\lambda, \sigma)-\Gamma(\lambda)-s(\lambda)\}+\Pi\{V(\lambda, \bar{\sigma})-\Gamma(\lambda)-s(\lambda)\}
$$




$$
\text { subject to } \quad s(\lambda) \geq \phi(1-\Pi)\{V(\lambda, \sigma)-V(\lambda, \bar{\sigma})\} .
$$

As in Section 5, the objective function is the firm's expected profit. The first term in brackets is the expected profit conditioned on the continuation of the incumbent manager, which is an event with probability $1-\Pi$. The second term in brackets is the firm's expected profit conditioned on managerial turnover, which causes a disruption of the system of incentives that reduces the firm's value to $V(\lambda, \bar{\sigma})-\Gamma(\lambda)-s(\lambda)$. This reduction in value captures the shareholders' cost with managerial turnover.

The manager's participation constraint (equation (12)) captures shareholders' gain from the probability of managerial turnover. With probability $\Pi$, the manager's decision to quit will be irrelevant to the firm's value because, in this event, the Board will take the initiative to trigger managerial turnover. Accordingly, the manager's reservation value is reduced by $\phi \Pi\{V(\lambda, \sigma)-V(\lambda, \bar{\sigma})\}$.

Expected profits decrease with the manager's compensation, implying that the participation constraint will be binding in the optimum. Hence, we can rewrite the maximization program as

$$
\max _{\{\lambda\}}(1-\Pi) V(\lambda, \sigma)+\Pi V(\lambda, \bar{\sigma})-\Gamma(\lambda)-\phi(1-\Pi)[V(\lambda, \sigma)-V(\lambda, \bar{\sigma})]
$$

whose first order condition is

$$
(1-\Pi) \frac{\partial V}{\partial \lambda}\left(\lambda^{\star}, \sigma\right)+\Pi \frac{\partial V}{\partial \lambda}\left(\lambda^{\star}, \bar{\sigma}\right)=\frac{\partial \Gamma\left(\lambda^{\star}\right)}{\partial \lambda}+\phi(1-\Pi)\left[\frac{\partial V}{\partial \lambda}\left(\lambda^{\star}, \sigma\right)-\frac{\partial V}{\partial \lambda}\left(\lambda^{\star}, \bar{\sigma}\right)\right] .
$$

As Proposition 3 shows, Program (13) implies that the probability $\Pi$ of managerial turnover increases bureaucracy and decreases managerial rents.

Proposition 3. Under Assumption 1, the probability $\Pi$ of managerial turnover increases bureaucracy (i.e., $\frac{\partial \lambda^{\star}}{\partial \Pi}<0$ ) and decreases managerial rents. 
Proof. See the Appendix.

The intuition for Proposition 3 is straightforward. If managerial turnover will happen regardless of the incumbent manager's will, his quitting threat is obviously weakened. In addition, a positive probability of managerial turnover induces the Board to increase the effectiveness of the system of incentives, making the firm more bureaucratic and less sensitive to the continuation of the manager at the company's helm. The impact of the probability of managerial turnover on the optimal organizational design further reduces the manager's bargaining power.

Other theories of bureaucracy do not share the prediction that bureaucracy and managerial turnover are positive correlated. For instance, in Tirole (1986), bureaucracy arises as a mechanism to limit collusion between employees and their supervisors. As Tirole points out in page 201, "Keeping relationships short has the advantage of restricting side transfers and, thus, of limiting the influence of coalitions in organizations." Since a probability of managerial turnover obviously shortens the life of relationships in the firm, Tirole's model predicts a negative correlation between bureaucracy and managerial turnover.

\section{Bureaucracy and leverage}

Although Proposition 3 demonstrates that managerial rents decrease with the probability of managerial turnover, adopting a policy of periodically replacing the management is not necessarily in shareholders' interest. In fact, differentiating the firm's expected profits (the value function of Program (13)) with respect to the probability of managerial turnover yields

$$
-(1-\phi)\left\{V\left(\lambda^{\star}, \sigma\right)-V\left(\lambda^{\star}, \bar{\sigma}\right)\right\}<0 .
$$

Other things equal, it is not optimal for shareholders to commit to a positive probability of managerial turnover. 
Nonetheless, Gilson (1989) shows that, in his sample of financially distressed firms, $52 \%$ of the managers lose their jobs. Harris and Raviv (1990) provide one justification for such a high turnover rate: Financial distress conveys a negative signal of the incumbent manager's ability, increasing the likelihood that it is optimal for shareholders to replace the incumbent management.

In this setting, leverage implies a positive probability of managerial turnover that is unrelated to the manager's quitting threat. Since the probability of financial distress increases with the firm's debt, Proposition 3 implies that more levered firms are more bureaucratic and their managers enjoy lower rents.

\section{Committing not to renegotiate salaries}

One could argue that, instead of bureaucratizing the firm to reduce managerial rents, the Board might be able to solve the rent extraction problem more efficiently by committing not to renegotiate the manager's incentive scheme. Free from the rent extraction problem, the Board could assure the efficient organizational design by making the manager's salary contingent on the organizational choice. An important question, thus, is whether firms can easily commit not to renegotiate the manager's salary.

As Stole and Zwiebel (1996) point out, labor contracts are non binding in nature and important employees have the ability to bargain directly with the Board. Moreover, a manager's ability to extract rents is not limited to her monetary compensation. By using the quitting threat, a manager may extract more perks or other indirect benefits from the corporation. Since it is difficult to imagine that a Board could commit along all these dimensions, a mechanism that commits the company to a specific wage schedule may not eliminate the manager's incentive to distort the organization. If so, reducing managerial agency costs may lead the 
Board to bureaucratize the firm. ${ }^{8}$

\section{Conclusions}

In the economics literature, the term "bureaucracy" has been associated with ex-ante optimal constraints on the employee's actions: the requirement to work in the company's facilities, the denial of access to superiors, etc. In this literature, bureaucracy implies that information is either destroyed or ignored. Yet, the term 'bureaucracy' is often associated with a system that generates rather than destroys information. Not only is this the sense of Weber's opening quote, but also the widespread perception that the recording of corporate actions and the filing of forms make a company "too bureaucratic". Consistent with this idea, this paper explores the role of bureaucracy in generating information.

In our framework, the extent to which firms document their actions emerges from a trade off between the gains of improving incentives and production efficiency. On the one hand, the recording of actions allows for input-based measures of performance that increase the effectiveness of the firm's system of incentives. On the other hand, recording actions and filing reports cost time and effort that could be used to enhance production. We show that managerial agency problems induce shareholders to bias this trade-off toward the benefits of improving incentives. Companies become overly bureaucratized and internal accounting systems, which may be the best example of using resources for documenting corporate events, are likely to be prioritized.

\footnotetext{
${ }^{8}$ An anecdotal case may help illustrate the pressure to renegotiate. Stewart (1991) reports that, after the debacle of Michael Milken, Drexel guaranteed its main traders the same level of the previous year bonuses (regardless of their performance). Probably, the offer was an attempt to avoid the departure of valuable employees, who might fear that their performance would be jeopardized by Drexel's financial distress.
} 
Perhaps more importantly, our analysis shows that the system of incentives of more bureaucratized firms relies more strongly on input-based performance measures. As a result, the model yields a measure of bureaucracy - the extent to which employees' pay depends on measures of input rather than output - which we believe that can be used to test the model's implications that relate the level of bureaucracy to firms' leverage and to the frequency of managerial turnover. 


\section{Appendix}

The proofs for Propositions 1, 2, and 3 follow.

\section{Proof of Proposition 1.}

It suffices to prove that, under Assumption $1, \frac{\partial \beta_{2}(\lambda, \sigma)}{\partial \sigma}>0$. Differentiating equation (4) yields

$$
\frac{\partial \beta_{2}(\lambda, \sigma)}{\partial \sigma}=\frac{\left[1+\left(\frac{\lambda}{\sigma}\right)^{2}\right] c^{\prime \prime}(a) \frac{d a}{d \sigma}+c^{\prime}(a) 2\left(\frac{\lambda}{\sigma}\right)^{2} \frac{1}{\sigma}}{\left[1+\left(\frac{\lambda}{\sigma}\right)^{2}\right]^{2}}>0 \Leftrightarrow \frac{a c^{\prime \prime}(a)}{c^{\prime}(a)}\left(-\frac{d a}{d \sigma} \frac{\sigma}{a}\right)<2 \frac{\lambda^{2}}{\lambda^{2}+\sigma^{2}} .
$$

Given $\frac{a c^{\prime \prime}(a)}{c^{\prime}(a)} \leq k$ and $\frac{\left(\lambda^{m i n}\right)^{2}}{\left(\lambda^{m i n}\right)^{2}+(\sigma)^{2}} \leq \frac{\lambda^{2}}{\lambda^{2}+\sigma^{2}}$ for any $\lambda \geq \lambda^{m i n}$, equation (A1) holds if $-\frac{d a}{d \sigma} \frac{\sigma}{a}<$ $\frac{2}{k} \frac{\left(\lambda^{m i n}\right)^{2}}{\left(\lambda^{m i n}\right)^{2}+(\sigma)^{2}}$.

Q.E.D.

Proof of Proposition 2.

A straightforward application of the envelope theorem on equation (6) yields

$$
\frac{\partial\{V(\lambda, \sigma)-V(\lambda, \bar{\sigma})\}}{\partial \lambda}=-r \beta_{2}^{2}(\lambda, \sigma) \lambda+r \beta_{2}^{2}(\lambda, \bar{\sigma}) \lambda=r \lambda\left[\beta_{2}(\lambda, \bar{\sigma})+\beta_{2}(\lambda, \sigma)\right]\left[\beta_{2}(\lambda, \bar{\sigma})-\beta_{2}(\lambda, \sigma)\right]>0
$$

where the inequality holds because, from Proposition $1, \frac{\partial \beta_{2}(\lambda, \sigma)}{\partial \sigma}>0$.

It then follows that $\phi\left\{V\left(\underline{\lambda}^{e f f}, \sigma\right)-V\left(\underline{\lambda}^{e f f}, \bar{\sigma}\right)\right\}<\phi\{V(\lambda, \sigma)-V(\lambda, \bar{\sigma})\}$ for any $\lambda>\underline{\lambda}^{e f f}$, where $\underline{\lambda}^{\text {eff }}$ is the most bureaucratized organizational design that maximizes firm value. This result and

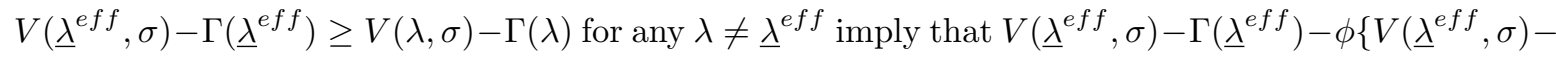
$\left.V\left(\underline{\lambda}^{e f f}, \bar{\sigma}\right)\right\}>V(\lambda, \sigma)-\Gamma(\lambda)-\phi\{V(\lambda, \sigma)-V(\lambda, \bar{\sigma})\}$ for any $\lambda>\underline{\lambda}^{\text {eff }}$, proving that $\lambda^{\text {sb }} \leq \underline{\lambda}^{\text {eff }}$.

To show that the optimal organizational design implies that the firm is overly bureaucratized (i.e., $\lambda^{s b}<\underline{\lambda}^{e f f}$ ), note that the first order condition of the shareholders' problem at $\underline{\lambda}^{e f f}$ is

$$
\frac{\partial V}{\partial \lambda}\left(\underline{\lambda}^{e f f}, \sigma\right)-\Gamma^{\prime}\left(\underline{\lambda}^{e f f}\right)-\phi\left[\frac{\partial V}{\partial \lambda}\left(\underline{\lambda}^{e f f}, \sigma\right)-\frac{\partial V}{\partial \lambda}\left(\underline{\lambda}^{e f f}, \bar{\sigma}\right)\right]=-\phi\left[\frac{\partial V}{\partial \lambda}\left(\underline{\lambda}^{e f f}, \sigma\right)-\frac{\partial V}{\partial \lambda}\left(\underline{\lambda}^{e f f}, \bar{\sigma}\right)\right]
$$

where the first two terms in equation (A2) vanish by construction of $\underline{\lambda}^{\text {eff }}$.

In section 4 , we showed that $\frac{\partial^{2} V(\lambda, \sigma)}{\partial \lambda \partial \sigma}<0$ under Assumption 1, which implies that $\frac{\partial V}{\partial \lambda}\left(\underline{\lambda}^{e f f}, \sigma\right)-$ $\frac{\partial V}{\partial \lambda}\left(\underline{\lambda}^{e f f}, \bar{\sigma}\right)>0$ and $-\phi\left[\frac{\partial V}{\partial \lambda}\left(\underline{\lambda}^{e f f}, \sigma\right)-\frac{\partial V}{\partial \lambda}\left(\underline{\lambda}^{e f f}, \bar{\sigma}\right)\right]<0$. Therefore, expected profits increase if the organizational choice changes from $\underline{\lambda}^{\text {eff }}$ to $\underline{\lambda}^{\text {eff }}-\epsilon$ with $\epsilon>0$ sufficiently small. 
Proof of Proposition 3.

Define $\Psi(\Pi, \lambda)=(1-\Pi) \frac{\partial V}{\partial \lambda}(\lambda, \sigma)+\Pi \frac{\partial V}{\partial \lambda}(\lambda, \bar{\sigma})-\frac{\partial \Gamma(\lambda)}{\partial \lambda}-\phi(1-\Pi)\left[\frac{\partial V}{\partial \lambda}(\lambda, \sigma)-\frac{\partial V}{\partial \lambda}(\lambda, \bar{\sigma})\right]$. Thus, the first order condition of the Board's maximization problem (equation (14)) can be written as $\Psi\left(\Pi, \lambda^{\star}\right)=0$. Applying the Implicit Function Theorem to $\Psi\left(\Pi, \lambda^{\star}\right)=0$ yields $\frac{d \lambda^{\star}}{d \Pi}=-\frac{\frac{\partial \Psi\left(\Pi, \lambda^{\star}\right)}{\partial \Psi\left(\Pi \Pi \lambda^{\star}\right)}}{\partial \lambda}$. Since $\lambda^{\star}$ solves the maximization problem that leads to $\Psi\left(\Pi, \lambda^{\star}\right)=0, \frac{\partial \Psi\left(\Pi, \lambda^{\star}\right)}{\partial \lambda}<0$, which implies that $\frac{d \lambda^{\star}}{d \Pi}<0$ if and only if $\frac{\partial \Psi\left(\Pi, \lambda^{\star}\right)}{\partial \Pi}<0$. The sign of $\frac{\partial \Psi\left(\Pi, \lambda^{\star}\right)}{\partial \Pi}$ is

$$
\frac{\partial \Psi\left(\Pi, \lambda^{\star}\right)}{\partial \Pi}=-(1-\phi)\left\{\frac{\partial V\left(\lambda^{\star}, \sigma\right)}{\partial \lambda}-\frac{\partial V\left(\lambda^{\star}, \bar{\sigma}\right)}{\partial \lambda}\right\}<0,
$$

where the strict inequality follows because Assumption 1 implies $\frac{\partial^{2} V\left(\lambda^{\star}, \sigma\right)}{\partial \lambda \partial \sigma}<0$, which, in turn, implies that $\frac{\partial V\left(\lambda^{\star}, \sigma\right)}{\partial \lambda}>\frac{\partial V\left(\lambda^{\star}, \bar{\sigma}\right)}{\partial \lambda}$ when $\bar{\sigma}>\sigma$.

To complete the proof, let $R(\Pi)=\phi(1-\Pi)\left(V\left(\lambda^{\star}, \sigma\right)-V\left(\lambda^{\star}, \bar{\sigma}\right)\right)$ be the manager's rent under the optimal organizational design. Therefore, $\frac{d R}{d \Pi}=\phi(1-\Pi) \frac{d \lambda^{\star}}{d \Pi}\left\{\frac{\partial V\left(\lambda^{\star}, \sigma\right)}{\partial \lambda}-\frac{\partial V\left(\lambda^{\star}, \bar{\sigma}\right)}{\partial \lambda}\right\}-\phi\left[V\left(\lambda^{\star}, \sigma\right)-\right.$ $\left.V\left(\lambda^{\star}, \bar{\sigma}\right)\right]<0$, where the inequality follows from $\frac{d \lambda^{\star}}{d \Pi}<0, \frac{\partial V\left(\lambda^{\star}, \sigma\right)}{\partial \lambda}-\frac{\partial V\left(\lambda^{\star}, \bar{\sigma}\right)}{\partial \lambda}>0$, and $V\left(\lambda^{\star}, \sigma\right)-$ $V\left(\lambda^{\star}, \bar{\sigma}\right)>0$. 


\section{References}

Denis, D.J., And Denis, D.K. "Performance Changes Following Management Dismissals." Journal of Finance, Vol. 50 (1995), pp. 1029-1057.

Edlin, A. And Stiglitz, J. "Discouraging Rivals: Managerial Rent Seeking and Economic Inefficiencies." American Economic Review, Vol. 85 (1995), pp. 1301-1312.

Felli, L. "Preventing Collusion Through Discretion." Mimeo, London School of Economics, 1996.

Gilson, S. "Management Turnover and Financial Distress." Journal of Financial Economics, Vol. 25 (1989), pp. 241-262.

Harris, M. And Raviv, A. "Capital Structure and the Informational Role of Debt." Journal of Finance, Vol. 45 (1990), pp. 321-349.

Holmstrom, B. "Moral Hazard and Observability." Bell Journal of Economics, Vol. 10 (1979), pp. 74-91.

—_ And Milgrom, P. "Multitask Principal-Agent Analysis: Incentive Contracts, Asset Ownership and Job Design." Journal of Law, Economics, and Organizations, Vol. 7 (1991), pp. 24-52.

Matthew, C., Hartzell, J. And Rosenberg, J. "The Impact of CEO Turnover on Firm Volatility." Mimeo, New York University, 2000.

Milgrom, P. "Employment Contracts, Influence Activities, and Efficient Organization Design." Journal of Political Economy, Vol. 96 (1988) pp. 42-61.

—_ And Roberts J. "The Efficiency of Equity in Organizational Decision Processes." American Economic Review, Papers and Proceedings, Vol. 80 (1990), pp. 154-159.

Prendergast, C. "A Theory of Responsibility in Organizations." Journal of Labor Economics, Vol. 13 (1995), pp. 387-400.

—_ And Topel R. "Favoritism in Organizations." Journal of Political Economy, Vol. 104 (1996), pp. $958-978$.

Shleifer, A. And Vishny, R. "Management Entrenchment: The Case of Manager-Specific Assets." Journal of Financial Economics, Vol.25 (1989), pp. 123-140.

Stole, L. And Zwiebel, J. "Organizational Design and Technology Choice under Intra-Firm Bargaining." American Economic Review Vol. 86 (1996), pp. 195-222.

Stewart, J.B. Den of Thieves. New York: Simon \& Schuster, 1991.

Tirole, J. "Hierarchies and Bureaucracies: On the Role of Collusion in Organizations." Journal of Law, Economics, and Organization, Vol. 2 (1986), pp. 181-214.

— . "Collusion and the Theory of Organizations." In J.J. Laffont, ed., Advances in Economic Theory: Sixth World Congress. New York: Cambridge University Press, 1992.

Warner, J, Watts, R. And Wruck, K. "Stock Prices and Top Management Changes." Journal of Financial Economics, Vol. 20 (1988), pp. 461-492.

Weber, M., Economy and Society. University of California Press, Berkeley, California, 1968. 